viscous, and a large solid clot with thin buffy coat, and frequently on the surface of the latter a stratum of albumen.

In the Anrsthetic Elephantiasis, the prime seat of the morbid deposit is the spinal cord and the ganglia and sheaths of the nerves. In the autopsies performed by Drs. Danielssen and Boëck, the veins of the spinal cord were found congested, particularly its posterior part; a thick, albuminous layer, several lines in thickness, was found between the arachnoid and pia mater; there was general infiltration of the membranes of the cord by albuminous fluid; and the cord itself was tough, almost as hard as cartilage, and in some cases reduced to the calibre of a quill. The grey substance of the cord was of a pale, dirty yellow colour, and all trace of bloodvessels, excepting in the middle, was lost. With such a state of morbid. alteration of the nervous centre, the characteristic phenomena of the disease, the anæmia, emuciation, atrophy of the muscles and skin, mortification of the skin, and necrosis of the bones or the extremities, are easily explained. In cases where the face, nares, and mouth were extensively reduced in sensibility and nutrition, the eyes being in a state of atrophy, the Casserian ganglion was found to be distended with albuminous exudation. The same albuminous deposit has been found within the sheaths of the nerves in other parts of the body, giving them a swollen appearance, and explaining at once the destroyed innervation of the surface and extremities, and the deep-seated pains so common in this disease, and particularly in its later stages. The same transparent albuminous exudation has been found in the subserous tissue of the lungs and liver, and in the substance of the lymphatic glands. The mucous membrane if pale, and less apt to ulcerate than in the tubercular form os disease; the eyeballs become opaque and atrophied, there may be a small ulcer in the septum nasi, but the nose never falls in; the spleen is usually hypertrophied; the liver sometimes fatty, and the kidneys always seriously diseased; the pancreas and salivary glands commonly escape; the blood in the anæsthetic form differs very litile from that in tubercular elephantiasis.

In selecting well-marked examples of the two forms of elephantiasis, the distinction between them is very evident; but in slighter cases, there is often a blending of the symptoms belonging to the two. In one out of six cases, according to Drs. Danielssen and Boëck, the disease commences with anresthesia of the hands or feet, and then passes into the tubercular form; in one case in twenty, the anæsthetic form takes the place of the tubercular; or aborted tubercles are developed in the course of the anæsthetic form. In a word, though frequently quite distinct, and pursuing an independent course, the symptoms of the two forms may be present in the same individual, or the one may pass into the other; moreover, parents afflicted with one form may have children in whom the other form is develeped. The tubercular is more common than the anæsthetic form.

\section{ON THE AVERAGE DURATION OF LIFE IN PATIENTS WITH SCIRRHOUS CANCER OF THE BREAST.}

BY JAMES PAGET, ESQ., F.R.S. ASSISTINT-SURGEON TO ST. BARTHOLOMEW'S HOSPITAL,

THE numbers of THE LANCET for May 22nd and June 19th, 1852, contain notices of a statement made by me, in a lecture at the College of Surgeons, that the average duration of cases of cancer of the breast, when the disease is left to itself, is thirteen months greater than that of cases in which the diseased breast is removed by operation. Soon after the delivery of the lecture, I found that I had fallen into error, through reckoning the averages from too small a number of cases, and through including in the estimates some cases which had been published only because they were examples of a long duration of life, when the cancerous breasts were not removed. When the lecture was printed, in $1853,^{*}$ I inserted in it what I believe to be a more nearly accurate statement of the average durations of life in the two classes of cases; but, observing that the erroneous statement is much oftener quoted than the more accurate one, and having reason to believe that the former is more frequently than the latter taken for guidance in practice, I am anxious to give the same circulation to what $\Gamma$ believe is nearly true, as (to my great regret) I gave to error.
Records which I have made or collected of 139 cases of scirrhous cancer of the breast, watched to their conclusions, or to their survivals beyond the average duration, give the follow. ing results :-

In 75 not submitted to operation, the average duration of life, after the patient's first observation of the disease, has been 48 months. In 64 submitted to operation, and surviving its immediate consequences, the corresponding average has been a little more than 52 months. The longest duration of life, in the former class, has been 216 months ; in the latter class, 146 ; the shortest, in the former, was 7 months; in the latter $7 \frac{1}{2}$.

The proportionate numbers of the deaths* in each year, after the first observations of the disease, may be represented by the following table:-

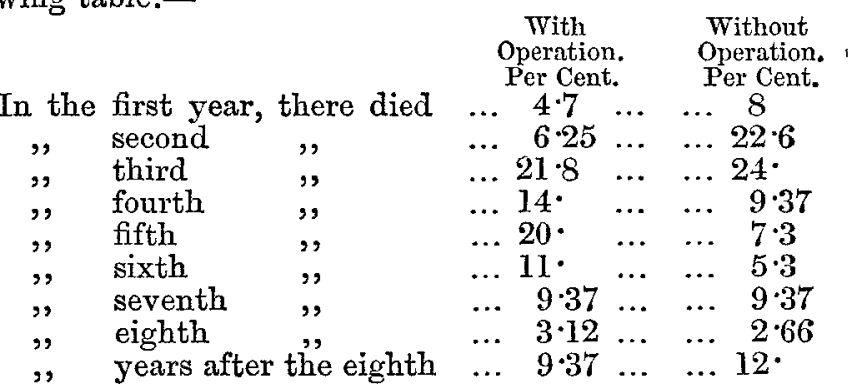

When the extremes of duration are so widely different as they are here shown to be, a perfectly reliable average cannot be obtained, unless the numbers of cases are, on both sides, larger than those supplied by my records.t I believe, therefore, that the results here stated are only near the, and truth that the collection of more cases will in some measure alter them.

Thus, it is nearly certain that the averages stated above are, on both sides, rather too low, for twenty of the patients (i. e., one-seventh of the whole number) are, or were, still living, after having survived the average time of duration with the disease. Moreover, as cases of the longest duration are the most likely to be lost sight of before their record is completed, it will generally happen that a collection of cases will include a disproportionately large number of those of short duration. Allowing, however, for these causes of reduction in the calculated average durations of life, there appears no reason to expect that any number of completed and unselected cases will prove an average duration of more than five years from the first observation of the disease.

The sources of error above referred to would, I think, especially reduce the estimate of the average duration of the cases in which no operation is performed; for unless cases are kept with an express intention of recording all that occur, without: any selection whatever, there will be a tendency to omit a disproportionate number of those which are not made interesting, either by operations, or by some of those striking events which are most common in acute cases. Hence, the records will generally contain too few of the most chronic cases in which no operation has been performed. I have expressly avoided this error in my own note-books, by avoiding everything like a selection of cases for record; but $I$ cannot be quite sure that the same rule has been observed in some of the records from which I have derived cases observed by others. I can find, however, no reason to believe that any full and accurate tables of cases will bring out, as a result, that patients, in whom: cancer of the breast is left to pursue its course, live longer, on an average, than those from whom it is removed. Rather, 1 believe that, if care be taken in the discrimination of the cases appropriate for the operation, and in the rejection of those that are unfit, there will appear a gradually-increasing, though it may be always a small, advantage in favour of the cases in which the breast is removed. Probably it may be ascribed, in some measure, to such care, that the additional and continued cases, which I have tabulated in the last two years and a half, make the average duration in those operated on rather longer, and that in those not operated on, rather shorter than it appeared in 1853

With regard to the rules that may be observed in the selection of the eases most fit for operation, I may refer to the published lecture; continued observations having only confirmed the statements made therein. I will only refer to one fact, which the table printed above shows-namely, that the pro-

* With the deaths, I have included in this table the numbers of those who are still living beyond the average period. The omission of them would have made no difference in relation to the questions concerning the influence of the remoral of the cancerous breast.

I I could have easily made the numbers larger by including doubtful, or only probable, cases of cancer of the breast, but tables so made up seem worse than useless. 
portion of deaths, in the first two years of the disease, is much less in those who are operated on than in those who are left; amounting in the former to less than eleven per cent., in the latter to more than thirty per cent. Such a result, while it justifies the operation in the cases of acute cancers which are not attended with evident cachexia, may be fairly set against the mortality from the operation itself, which I still believe to be not less than ten per cent.

\section{ON THE}

\section{CHEMICAL CONDITIONS OF CHOLERA ATMOSPHERES.}

BY ROBERT DUNDAS THOMSON, M.D., F.R.S. I. \& E., PROFESSOR OF CHEMISTRT IX ST. THOMAS'S HOSPITAL COLLEGE, VICE-PRESIDEYT OF THF BRITISH MIETEOROLOGICAI SOCIETr, ETC.

TuE chemical conditions of cholera atmospheres is a question of intense interest in the subject of public health; but with the exception of the unpublished experiments of Dr. Prout, during the epidemic of 1832 , comparatively little attention appears to have been bestowed on it. One of the most striking circumstances connected with the occurrence of the disease is, that no change very palpable to the senses prevails; and it has even been remarked, that the weather has usually been exceedingly agreeable. In London, at St. Thomas's Hospital, the neighbourhood of which afforded a large supply of cholera cases, the relative weight of the air, in August, 1854-a cholera month, and in August, 1855, when the metropolis was in an exceedingly healthy condition, is exhibited in the following table in grains per cubic foot:-

\begin{tabular}{|c|c|c|c|c|c|c|c|}
\hline $\begin{array}{l}\text { 1854. } \\
\text { Week ending }\end{array}$ & & $\begin{array}{l}\text { Weig } \\
\text { foo }\end{array}$ & $\begin{array}{l}\text { it of cubic } \\
\text { in grains. }\end{array}$ & $\begin{array}{c}1855 \\
\text { Weck ending }\end{array}$ & & $\begin{array}{l}\text { Wei } \\
\text { foo }\end{array}$ & $\begin{array}{l}\text { ht of cubi } \\
\text { in grains }\end{array}$ \\
\hline Aug. 5th & & $\ldots$ & $522 \cdot 9$ & Aug. 4th & & $\ldots$ & $516 \cdot 9$ \\
\hline 12th & ... & & $526 \cdot 7$ & 11 th & & & $524 \cdot 3$ \\
\hline 19 th & ... & $\ldots$ & $525^{\circ}$ & 18th & & $\cdots$ & 5 \\
\hline 26 th & $\ldots$ & $\ldots$ & $523 \cdot 5$ & 25 th & $\ldots$ & $\cdots$ & $519 \cdot 2$ \\
\hline Sept. 2nd & ... & $\ldots$ & $525 \cdot 2$ & Sept. Ist & $\ldots$ & $\ldots$ & $523 \cdot 0$ \\
\hline 9th & $\ldots$ & $\ldots$ & $530 \cdot 3$ & 8th & $\cdots$ & $\ldots$ & $531 \cdot 6$ \\
\hline Mean & & $\ldots$ & $525 \cdot 6$ & Mean & $\cdots$ & ... & 52 \\
\hline
\end{tabular}

The result, as decluced from this table, which has been cal culated approximately from the barometric pressure, dry and wet bull thermometers, is analogous to that obtained by Dr. Prout, in 1832, as I was informed by himself. Corresponding observations have been made by Mr. Glaisher, at Greenwich, and the same conclusions arrived at; from which it would appear that this superior weight of a given bulk of common air was not a local phenomenon, but was diffused to a considerable distance.

Another character distinguishing September, 1854, from the corresponding period of 1855 , was the absence of any atmospheric action on ozone test-paper in the former season while during 1855, the oxidizing influence of the air has never been absent at St. Thomas's Hospital. During September, 1854, however, when no ozone could be detected in London, its action was sometimes faint, and often very strongly marked, at Lewisham, near Greenwich. Throughout the same periods the air was exceedingly stagnant; and it has since been observed by Mr. Glaisher, and also at Vienna, that rapid atmospheric movement is pretty generally accompanied by an oxidizing condition of the air.

With reference to the chemical composition of the atmospheres of inhabited localities and malarious districts, experiments have usually been conducted on the constitution of the gases which enter into the composition of the air. But the results seem to have thrown little light on the possibility of the production from such canses of any disease characterized by a regular sequence of symptoms. So far as our knowledge warrants, gases can either act only as asphyxiating media by the exclusion of oxygen, or as slow or rapid poisons. The cause capable of inducing disease, formed on a peculiar type, analogy leads us to infer, must be in an organized condition, either in a solid form, or in a finely-diffused, or vaporific state. The fact observed, that in malarious atmospheres sulphuric acid speedily become black, also points to the propriety of examin ing the air in such situations, with the view of filtering from it solid or condensible matter. In the epidemic of 1849-50, I examined the exterior air of an infected district with this object in view to the extent of many cubic feet; but the result was comparatively negative, and led to the inference that the examination of large masses of air could alone hold out any prospect of a successful isstue.

For this purpose, in 1854, air was passed through carefully-prepared distilled water, contained in Wolfe's bottles, by means of a large aspirating apparatus, of the capacity of sixteen cubic feet, which was kept constantly in action during the day for several months. Occasionally freezing mixtures were applied to portions of the apparatus, and a tube filled with pumice moistened with sulphuric acid, placed near the aspirator, completed the series. A range of glass tubes conducted the air from a cholera ward into the aspirator. The ward was 32 feet long, 20 wide, and 9 high. The air was drawn from the centre of the ward, near the ceiling; and when the apartment was filled with cholera patients, the air, after traversing several layers of distilled water, speedily charred the sulphuric acid, and deposited a variety of solids in all the Wolfe's bottles, which could even be detected in some measure by the eye. The objects consisted of blue and red cotton fibres, from the dresses of the inmates, portions of hair, wool, fungi, sporules of fungi, abundance of vibriones, or lower forms of animal life, with particles of silica and dirt. In this and in all the experiments conducted on the air of closed apartments, the distilled water was rendered strongly acid, from the presence of sulphuric and sulphurous acids, derived from the products of gas and coal combustion. The distilled water used in these experiments was boiled for some time previous to being introduced into the apparatus, and was divided into two portions, one part being placed in a stoppered bottle, beside the Wolfe's bottles, through which the air was conducted, the sediment, if any, being afterwards examined and compared with that resulting from the experiment. When the ward was only partially filled, vegetable epiderm, vegetable cellular tissue, fragments of cotton, linen, vegetable hairs, sponge spiculæ, minute fungi, spiral vessels, sporules, spore cases, animal epithelium, oil-globules, and silicious particles were conspicuous, while vibriones were entirely absent, or at least mere traces could be discriminated. This is an interesting result, since, in the first case only $98^{\circ} 6$ cubic feet were examined, and of the partially empty ward 240 cubic feet passed through the apparatus. When the ward was empty, cotton fibres, wool, a trace of fungus, with carbonaceons and silicious psirticles, were alone observable, the amount of air examined being 304 cubic feet. The air external to the ward, and in the immediate neighbourhood, afforded, from 560 cubic feet, one cotton fibre, one of wool, a crystalline body, probably a sponge spicula, sporules, beautiful mycelia of fungi in various stages of development, and some carbonaceous matter. The distilled water, in this instance, likewise yielded a strongly acid reaction, produced by sulphur acids. The possible infuence of sewer atmospheres predicted interesting results from an examination of such air; and accordingly, it was found that the predominating feature of this experiment was animal life, in the form of swarms of vibriones, in various stages of advancement. The chemical reaction in this case, unlike that in the preceding experiments, was invariably alkaline, due to the evolution of ammonia from the nitrogenous matters contained in the sewage liquors. These experiments render it sufficiently obvious, that organic living bodies constantly surround us in close apartments, and particularly that animal matter, under certain circumstances, exists in the air. It is scarcely legitimate to infer, that the absence from the air of matter capable of communicating cholera has been proved by these experiments, since it is certain that nitrogenous materials, distinct from the germs of vibriones, must have been present, to supply food to these living beings. The researches show, that foreign animal matter, injurious to health, may speedily be concentrated in certain localities, which will undoubtedly assist, in conjunction with meteorological conditions, in the production and propagation of disease. Pathological investigation, carefully conducted by my colleague, $\mathrm{Mr}$. Rainey, detected, in one case, an entozoon in the glottis, the only analogues of which have hitherto been found in the substance of the muscles of animais, a fact which would seem to indicate that the germ of this creature had been derived from the atmosphere, or at least directly from external sources. Careful pathological examination failed to detect in the mouth or air-passages sporules, germs, or living beings, in those patients who died of cholera. The experiments of Mr. Rainey prove that organic solutions readily yield a soil for the growth of such atmospheric sporules as were detected in these investigations; and that when such solutions are brought only in contact with filtered atmospheric air, they are not attacked by mouldy growths. For a detail of the following interesting experiments, $\mathrm{I}$ am indebted to $\mathrm{Mr}$. Rainey ; they may be cited as striking evidence against the theory of equivocal generation, 